\author{
Kátia Reis de Souza ${ }^{a}$ \\ (iD) http://orcid.org/0000-0002-2084-2606 \\ Andréa Maria dos Santos Rodrigues ${ }^{\mathrm{a}}$ \\ (iD) http://orcid.org/0000-0001-8254-341X \\ Maria Blandina Marques dos Santos ${ }^{\mathrm{a}}$ \\ (iD) http://orcid.org/0000-0002-0065-5635 \\ Eliana Guimarães Felix ${ }^{a}$ \\ (iD) http://orcid.org/0000-0002-3548-1356 \\ Regina Helena Simões Barbosa \\ (iD) http://orcid.org/0000-0002-1161-7220 \\ Verônica Silva Fernandez ${ }^{\text {b }}$ \\ (iD) http://orcid.org/0000-0002-2101-6728 \\ Walcyr de Oliveira Barros ${ }^{c}$ \\ (iD) http://orcid.org/0000-0002-5893-2260
}

a Fundação Oswaldo Cruz (Fiocruz), Escola Nacional de Saúde Pública Sergio Arouca, Centro de Estudos da Saúde do Trabalhador e Ecologia Humana. Rio de Janeiro, RJ, Brasil.

b Universidade Federal do Rio de Janeiro (UFRJ), Instituto de Estudos em Saúde Coletiva. Rio de Janeiro, RJ, Brasil.

' Universidade Federal do Rio de Janeiro (UFRJ), Escola de Enfermagem Anna Nery. Rio de Janeiro, RJ, Brasil.

Contato:

Kátia Reis de Souza

E-mail:

katreis@ensp.fiocruz.br

Os autores declaram que o trabalho contou com financiamento do Edital Inova ENSP/Fiocruz, no período de 2013 à 2016, com contratação de bolsas e serviços e concessão de passagens e diárias. Não há conflitos de interesses.

Os autores informam que o trabalho não foi apresentado em evento científico e que não foi baseado em dissertação ou tese.

\section{Oficinas em saúde do trabalhador: ação educativa e produção dialógica de conhecimento sobre trabalho docente em universidade pública}

\author{
Workshops on workers' health: educational action and dialogical \\ production of knowledge on teaching work at a public university
}

\section{Resumo}

Objetivo: analisar a abordagem metodológica "Oficinas em saúde do trabalhador" e seus resultados acerca das relações entre trabalho docente e saúde em universidade pública. Métodos: pesquisa social de caráter qualitativo e de natureza pedagógica e participativa. "Oficinas em saúde do trabalhador" são espaços onde trabalhadores e pesquisadores discutem temas de trabalho relacionados à saúde, pautados em investigação participativa e pedagogia freireana e em fundamentos do campo da Saúde do Trabalhador, principalmente o modelo operário de conhecimento e a teoria de Gramsci. Foram realizadas quatro reuniões com oito docentes pertencentes ao mesmo instituto de uma universidade federal localizada no estado do Rio de Janeiro. Resultados: no plano epistemológico, analisaram-se importantes temas acerca do trabalho e da saúde docentes, sendo eles: precarização da infraestrutura universitária e as condições de trabalho docente; relações coletivas e conflitos; sentidos e ambivalência do trabalho docente; queixas de saúde e intensificação do trabalho. Conclusão: este estudo possibilitou o desenvolvimento de abordagem metodológica de caráter dialógico e participativo. Embora o estudo esteja circunscrito a um pequeno grupo, o método propiciou identificar e analisar importantes aspectos do trabalho e da saúde docente que constatam transformações no trabalho em universidade, apontando para a necessidade de estudos de maior alcance.

Palavras-chave: saúde do trabalhador; docentes; universidade pública; metodologia participativa; precarização do trabalho.

\begin{abstract}
Objective: to analyze the methodological approach "Workshops on workers' health" and its results regarding the relationship between health and teaching in public universities. Methods: social study of qualitative, pedagogical and participatory approach. "Workshops on workers' health" are spaces where workers and researchers discuss the work and health relation in accordance with participative research, Freire's pedagogy and Workers' Health concepts, especially the Workers' Model of Knowledge and Gramsci's theory. Four meetings were held with eight professors of the same institute in a federal university situated in the state of Rio de Janeiro, Brazil. Results: epistemologically, important subjects concerning the work and health of teachers were analyzed, namely: university infrastructure precarization and teaching work conditions; collective relations and conflicts; teacher work meanings and ambivalence; health complaints and work intensification. Conclusion: this study enabled the development of a dialogical and participatory methodological approach. Although this study was limited to a small group, the method enabled the identification and analysis of important aspects of work and health of teaching at the university, showing the transformations in university work and indicating the need for studies of larger scope.
\end{abstract}

Keywords: occupational health; teaching; public university; participatory methodology; work precarization. 


\section{Introdução}

Em termos históricos, metodologias de pesquisa a respeito do trabalho que reconhecem o próprio trabalhador como sujeito do conhecimento e da ação estão presentes desde o século XIX, época em que Marx viveu ${ }^{1}$. De fato, a experiência que ficou conhecida como "Enquete Operária" e que se realizou por meio do questionário que Marx formulou em 1880, a pedido da La Revue Socialiste na França, é ainda hoje importante referência para os estudos de caráter participativo que se realizam junto a trabalhadores. As perguntas contidas no questionário tinham como objetivo estimular os participantes a descreverem o que conheciam a respeito das condições materiais de trabalho, valorizando sua própria experiência, de modo a tomarem consciência de sua situação social, permitindo ainda à classe trabalhadora o autoconhecimento ${ }^{2}$. Para Alves e Jackson Filho ${ }^{3}$, a enquete operária é atual por algumas razões, entre elas: "explora problemas de saúde e de vida que continuam presentes no mundo contemporâneo; relaciona problemas de saúde e de vida dos operários ao processo de produção capitalista e valoriza o saber dos trabalhadores" (p. 27).

Na América Latina e no Brasil, registram-se experiências pioneiras desenvolvidas por Paulo Freire que integram, no mesmo processo, investigação, participação e ação educativa. Vale mencionar, sobretudo, os trabalhos realizados nos anos de 1960 e 1970, junto a trabalhadores camponeses no Chile e Peru ${ }^{4}$, e também com operários no Brasil ${ }^{5}$. Distingue-se, nas obras de Paulo Freire, uma pedagogia problematizadora e dialógica sobre o trabalho acerca das relações de exploração e de dominação com vistas à sua transformação. Nessa vertente, o processo de produção do conhecimento propicia a transformação dos sujeitos pela atividade crítica e dialógica.

No que concerne, especificamente, aos estudos participativos sobre a relação trabalho e saúde, no Brasil é possível afirmar uma tradição de estudos procedentes da experiência operária e sindical italiana, a partir da década de 1980, por ocasião da publicação do livro "Ambiente de trabalho: a luta dos trabalhadores pela saúde" 6 , obra que ficou conhecida como "Modelo Operário Italiano" (MOI). De acordo com Souza e Mendonça ${ }^{7}$, o MOI constitui-se como importante referência para o desenvolvimento de metodologias e perspectivas de produção de conhecimento sobre a relação saúde-trabalho que impliquem na participação de trabalhadores e pesquisadores. Por certo, na obra de Oddone e colaboradores ${ }^{6}$, desenvolveu-se uma teoria de formação de trabalhadores que têm como princípio fundamental o próprio trabalho e os trabalhadores como sujeitos autônomos da análise e da transformação da nocividade dos ambientes de trabalho.
Sem a pretensão de esgotar referências metodológicas advindas do MOI, registraram-se aqui alguns conceitos e estratégias que sobressaem na literatura, como a concepção de "Comunidades Ampliadas de pesquisa" (CAP), uma derivação do conceito de "Comunidade Científica Ampliada"6. De acordo com Muniz et $\mathrm{al}^{8}$, a CAP constitui-se em um dispositivo metodológico que tem início no âmbito do Programa de Formação em Saúde, Gênero e Trabalho nas Escolas $^{9}$. Para os autores ${ }^{8}$, essa abordagem concilia pesquisas científicas e formação de trabalhadores, tendo como foco as relações entre trabalho e saúde nas situações concretas de trabalho que vivenciam. Seu principal propósito é compreender e transformar as relações entre o trabalho e os processos de saúde-doença, reunindo pesquisadores e trabalhadores em processo conjunto de coanálise. Do mesmo modo, é digna de nota a ferramenta metodológica denominada "Encontros Sobre o Trabalho" (EST) ${ }^{10}$ que foi criada a partir de uma avaliação sobre os limites do conceito de "Comunidade Científica Ampliada"6. Essa proposta metodológica tem como perspectiva transformar o trabalho, por meio da vital interlocução entre os saberes formais, gerados por diversos campos de conhecimento, e os saberes advindos da experiência dos trabalhadores.

Os estudos citados apresentam diversos traços comuns, ganhando destaque os aspectos alusivos à formalização da experiência e do conhecimento dos trabalhadores no diálogo com pesquisadores, a socialização das informações a respeito do processo de trabalho e a reflexão sobre a saúde em perspectiva coletiva. Observa-se que todos preceitos metodológicos mencionados são importantes referências deste estudo.

Considerando um retrato geral da relação entre trabalho e saúde docente identificada na literatura, em um primeiro plano, os estudos reportam-se às mudanças ocorridas no mundo do trabalho provocadas pelo processo de globalização da economia e Reforma de Estado ${ }^{11,12}$, à sofisticação tecnológica ${ }^{13}$ e à decadência das relações humanas cooperativas e solidárias ${ }^{14}$, que são substituídas por relações competitivas que resultam no que alguns autores denominam por precarização das relações de trabalho ${ }^{15-17}$. Merece atenção também a observação sobre desgaste físico e emocional a que professores estão submetidos em seu ambiente de trabalho, sendo bastante significativas referências a transtornos relacionados ao estresse, como é o caso das depressões, ansiedade, fobias, distúrbios psicossomáticos e a síndrome de burnout ${ }^{18,19}$. De uma forma geral, o que se percebe são análises alusivas à nova organização do trabalho em universidades públicas, tais como acúmulo de tarefas, sobrecarga de trabalho e exigências por metas de produtividade nas publicações ${ }^{20}$, levando à intensificação do trabalho ${ }^{21,22}$. 
Bosi $^{23}$ assegura que se discute pouco a forma como as transformações estruturais afetam o cotidiano do trabalho acadêmico e, em menor proporção, suas repercussões na saúde, do ponto de vista qualitativo dos próprios docentes. Para Laurell e Noriega $^{24}$, gerar conhecimento sobre a relação trabalho e saúde constitui-se, sobretudo, em tarefa de criação coletiva e desafio metodológico. Nesse sentido, este estudo teve como objetivo analisar a abordagem metodológica "Oficinas em saúde do trabalhador" e seus resultados acerca das relações entre trabalho docente e saúde em universidade pública.

\section{Métodos}

Desenvolveu-se uma pesquisa social de caráter qualitativo e de natureza pedagógica e participativa. Nesse enfoque, os temas surgem espontaneamente, não existindo um roteiro prescrito de questões. Os temas levantados são denominados "temas geradores" 4 , que podem ser compreendidos como unidades de registro primárias para a análise qualitativa do conteúdo das discussões ${ }^{25}$.

O estudo fundamentou-se na realização de "Oficinas em Saúde do Trabalhador", que são concebidas nos espaços onde trabalhadores e pesquisadores reunidos discutem temas de trabalho relacionados à saúde, pautados em elementos da investigação participativa e da pedagogia freireana ${ }^{4,5,26}$, bem como dos fundamentos do campo da saúde do trabalhador ${ }^{6,24}$, construindo um processo que, por meio do diálogo, venha possibilitar produção de conhecimento e ação educativa com vistas ao fortalecimento dos coletivos de trabalho e à defesa da saúde.

O aporte teórico central constitui-se na tese de Gramsci de acordo com a qual o trabalho consiste na matéria principal dos processos formativos e no "princípio educativo"27. Assume-se, portanto, a centralidade da categoria trabalho como fundamento do processo formativo que possibilite ao trabalhador refletir sobre o próprio labor.

Deve-se ter presente, ainda, que a designação do termo "Oficinas" possui inspiração nos chamados "círculos de cultura" procedentes, também, da obra de $\mathrm{Gramsci}^{27}$ (p. 35). Em termos práticos, a intenção é criar as condições necessárias para que o grupo opere a análise crítica a respeito da vida no trabalho. Cabe mencionar que Freire ${ }^{4,5}$ também lançou mão do conceito de "círculos de cultura", proveniente do pensamento de Gramsci e que Oddone e colaboradores $^{6}$ adotaram como parâmetro a alguns conceitos advindos da mesma tradição filosófica gramsciana, tais como: socialização do conhecimento; observação espontânea; e grupo homogêneo de trabalho ${ }^{6}$.
Aquilo que se pretende afirmar é que o pensamento e as obras de Marx ${ }^{1}$, Gramsci ${ }^{27}$, Freire ${ }^{4,5}$ e Oddone $^{6}$, base teórica deste estudo, constituem importante genealogia filosófica para os estudos atinentes à relação trabalho-saúde e metodologias de pesquisa de caráter educativo, participativo e dialógico.

Nas Oficinas, que se efetivaram pelo desenvolvimento de reuniões com grupos, elegeu-se o diálogo como categoria privilegiada do processo de produção de conhecimento e da ação educativa. Para Brandão e Streck, "em uma pesquisa de cunho pedagógico, adota-se o diálogo como relação fundamental" ${ }^{28}$ (p. 13). Nessa vertente, os grupos de discussão são fontes de conhecimento e fornecem elementos a serem objetos de interpretação crítica, conferindo uma conotação epistemológica ao diálogo $0^{4,5,26}$.

No que tange ao estudo de campo, o trabalho foi realizado em uma instituição federal de ensino superior (Ifes), localizada no Rio de Janeiro, que contava com 76 docentes no período da pesquisa. O critério de inclusão no estudo foi ser docente ativo e pertencer ao mesmo instituto, respeitando-se o pressuposto teórico alusivo à constituição de grupo homogêneo de trabalho, ou seja, estar submetido a mesma organização e experiência de trabalho ${ }^{6}$. Participaram do estudo oito docentes que exerciam o cargo de professor do magistério superior, com vínculo de trabalho estável, e com regime de trabalho de quarenta horas semanais, sendo cinco professoras e três professores, na faixa de idade entre trinta e cinquenta anos. Todos com titulação de doutorado, com tempo de trabalho nessa universidade variando entre cinco e dez anos, embora todos já atuassem há mais de dez anos como docentes. Todos os professores estavam inseridos tanto na graduação quanto em programa de pós-graduação. Foram realizadas quatro reuniões durante o segundo semestre de 2016. As reuniões tiveram a duração de duas horas e foram realizadas nas instalações do próprio instituto.

Observa-se que foram criados alguns artifícios para proteção dos participantes e do local do estudo: usou-se a letra D (docente) acompanhada de um número que corresponde a uma ordem aleatória criada para identificação na transcrição das falas. Quanto à universidade, contexto do estudo, definiu-se pela sigla fictícia UX, já que foi demandado pelos próprios docentes que não se mencionaria a verdadeira identidade institucional.

Cabe registrar, ainda, que as Oficinas fazem parte de um conjunto de abordagens de pesquisa e intervenção desenvolvidas junto a docentes de universidade pública no âmbito de um grupo de pesquisa, interdisciplinar e multicêntrico, desde o ano de 2013. Nesse processo, estão sendo atualizadas e desenvolvidas estratégias e tecnologias de 
investigação participativa em saúde, principalmente aquelas procedentes do MOI, tais como as "cadernetas de saúde e trabalho" e a consolidação da "comunidade ampliada de pesquisa"29.

Este estudo obteve aprovação do Comitê de Ética em Pesquisa da Escola Nacional de Saúde Pública Sergio Arouca, Fundação Oswaldo Cruz (ENSP/Fiocruz), sob o número CAAE: 19501813.5.0000.5240, em 2013.

\section{Resultados e discussão}

Durante as Oficinas teve-se acesso a importantes temas de diálogo acerca do trabalho e saúde de docentes no contexto da universidade pública. No entanto, nos limites deste manuscrito, apresentamos aqueles temas e sequências de diálogo que marcaram mais fortemente os debates, sendo eles: precarização da infraestrutura universitária e as condições de trabalho docente; relações coletivas e conflitos; sentidos e ambivalência do trabalho docente; queixas de saúde; intensificação do trabalho e jornada laboral. Cabe destacar, ainda, que foram pontuados os principais aspectos da ação educativa adotada, sendo eles: diálogo, problematização e reflexividade crítica $^{4,5}$.

No que diz respeito ao curso de desenvolvimento das Oficinas pode-se afirmar que, embora as reuniões tenham sido pactuadas previamente com os docentes, observou-se uma resistência inicial em falar sobre o trabalho, mas que logo foi superada por um clima de colaboração e pelo diálogo descontraído nas quatro reuniões. $\mathrm{O}$ fato de serem docentes submetidos a mesma organização e processo de trabalho favoreceu o desenvolvimento da crítica coletiva.

O tema que tomou grande parte do diálogo com os professores foi, precisamente, aquele relacionado à precarização da infraestrutura universitária e às condições de trabalho docente. Os participantes reportaram-se à história da UX e ao contexto político do país, bem como ao ordenamento de políticas públicas para o ensino superior. Foram constantes referências críticas à emergência do Programa de Apoio ao Plano de Reestruturação e Expansão das Universidades Federais (Reuni), instituído pelo Decreto $n^{\circ} 6.096$, de 24 de abril de $2007^{30}$. De fato, tanto a interpretação dos docentes quanto a literatura sobre o tema afirmam que tal política não gerou o necessário financiamento ao estabelecer o crescimento numérico das universidades no Brasil e a abertura de novas vagas para alunos, sem a equivalente criação de vagas para professores; ao contrário, verificaram-se sucessivos cortes de verbas, que tiveram como consequência o abandono da infraestrutura física dos campi ${ }^{21,31}$. Complementarmente, problematizou-se acerca da reforma do aparelho de Estado de caráter neoliberal iniciada no ano de 1995, que continua regulando o trabalho docente por meio de um grande número de leis e decretos. Os professores interpretaram que o processo de precarização da universidade não é somente uma questão de falta de recurso, pois trata-se de um projeto de maior alcance, de desmonte social da universidade e do ensino superior público no Brasil. Estimulou-se a continuidade do debate por meio da formulação de perguntas $(\mathrm{P})$, considerando que o método dialógico desenvolve-se no questionamento crítico sobre a realidade e na liberdade das interpretações daqueles que vivem o cotidiano dos problemas ${ }^{5}$.

(P) Qual a visão de vocês sobre essa
precarização? Acho que existe um processo que não começou há pouco tempo. Existe um processo de precarização mesmo [...] A gente é vítima do processo de destruição da universidade pública. E estamos recebendo as pancadas. O processo está em marcha aí. Em quanto tempo a universidade pública resiste? [...] Tem a ver com um processo que é muito mais complicado ainda que o do aporte de dinheiro. É uma questão de enxergar a profissão de forma diferente. (D7)

Com base na literatura, problematizou-se que a precariedade das condições de trabalho constitui-se em uma estratégia de dominação que sujeita os trabalhadores à degradação da vida social, nos planos material e moral. Para tal, conta com a adesão individual dos trabalhadores e o enfraquecimento dos laços coletivos de trabalho. Trata-se, como na acepção de Druck, da "precarização social do trabalho" elemento central da nova dinâmica do capitalismo ${ }^{32}$. Ao dialogar-se sobre aquilo que os estudos dizem a respeito da precarização do trabalho docente e os relatos acerca do cotidiano acadêmico, percebia-se um processo de educação recíproca, conforme preconizado pelo $\mathrm{MOI}^{6}$. Os participantes solicitavam artigos científicos sobre o tema para aprofundamento dos debates.

"Poderíamos ler sobre essa reconfiguração [do trabalho em universidades], que é algo que vemos na prática, mas não conseguimos teorizar sobre" (D1).

Confirmou-se a importância da relação entre teoria e prática no diálogo, outro tópico capital da ação educativa crítica que adota o trabalho como matéria pedagógica central. Adicionalmente, mencionaram-se estudos que confirmam a infraestrutura universitária deficiente como geradora de insatisfação e com repercussões na saúde dos professores ${ }^{33,34}$. Todos os participantes 
relatavam a diversidade de problemas enfrentados no cotidiano com exemplos concretos e compartilhavam estratégias de enfrentamento, tal qual a montagem de kits particulares transportados diariamente para as salas de aula (extensão elétrica, tomada, adaptador, entre outros). Essas estratégias foram refletidas e criticadas de maneira que não se tornassem naturalizadas. Incentivou-se a socialização dos problemas e das estratégias de defesa da saúde. Desse modo, intenciona-se ampliar a capacidade de análise e de ação sobre o trabalho pelo processo de partilha da experiência.

Da infraestrutura física, por exemplo, tem um monte de problemas [...] a gente tem sala de aula com divisória, você está dando aula e o aluno não consegue te ouvir, você tem que falar mais alto. (D5)

O ar condicionado foi uma briga dos alunos. Os alunos fizeram uma greve para exigir. (D1)

Nesse ponto do diálogo, ganhou destaque a conquista dos alunos para obtenção de ar refrigerado para as salas de aula. Enfatizou-se que as saídas para melhoria das condições de trabalho devem ser coletivas e não individuais. Além do que, no campo da saúde do trabalhador, postula-se que a saúde está estreitamente vinculada à capacidade organizativa dos próprios trabalhadores como sujeitos coletivos da ação ${ }^{24}$. Convém destacar também que, pelo ângulo do aporte teórico pedagógico adotado, dialoga-se sobre os conteúdos definidos pelos próprios participantes a partir de situações reais de trabalho e do estímulo a questionamentos críticos ${ }^{4,5}$.

"O que é que a gente faz? [...] ao longo do tempo isso obviamente reflete na saúde daquele profissional. Porque além desses problemas de estrutura física, você tem que lidar com uma série de outros problemas" (D5).

Vale destacar que outro problema bastante mencionado foi a redução do quantitativo de funcionários na universidade, o que acarreta sobrecarga de trabalho administrativo aos professores e conflitos entre esses dois grupos.

Você quer um data show pra dar aula, "pra que professora? Vai para o quadro, é preguiça”. [...] Eles [os funcionários] não conseguem entender. Então parece que tem uma guerra entre funcionários e professores. (D2)
(P) Existe esse debate aqui? De se pensar que ele é parte da formação dos alunos? Que ele [funcionário] é educador também?

Não tem. (D2)

Observa-se que, sob o prisma da teoria de educação adotada, levou-se a termo a pedagogia da problematização que pode ser definida, brevemente com Freire, como reflexão crítica coletiva ${ }^{4,5}$. A prática problematizadora propõe aos trabalhadores refletir a sua situação como problema. O tema alusivo aos conflitos entre docentes e funcionários gerou controvérsias no grupo. Refletiu-se sobre a divisão social do trabalho em universidade, problematizando a representação que os participantes têm sobre o trabalho coletivo. Avalia-se que esse tema foi pouco trabalhado nas Oficinas e que deve ser retomado em novos encontros, considerando, com Santana e Druck ${ }^{16}$ que trabalhadores técnico-administrativos, junto com outros grupos, também em situação de precarização, principalmente terceirizados, estão no cerne do confronto contra o trabalho degradado nas universidades. Todavia, esse diálogo aconteceu na primeira oficina, já na reunião seguinte a professora apontou para uma mudança de visão e reportou essa mudança ao debate ocorrido.

Sabe o que eu queria te falar, te dar um retorno. Foi engraçado que na reunião passada [...] eu discordei, - "Eu não vejo diferença entre docentes e funcionários". Foi muito engraçado, porque assim, duas semanas depois, nessa de preparar aula, o computador e o data show não funcionavam. E eu falei para os funcionários "Gente, vocês são meus anjos, o que eu faria sem vocês?”. Era de manhã. Aí os funcionários falaram, - "Ai, que bom ter alguém que reconheça a gente, porque a maioria acha que é obrigação e olhe lá". (D2)

No que concerne às relações de trabalho, problematizou-se sobre a importância do fortalecimento dos coletivos para fazer frente ao quadro de precarização em universidade. Em termos práticos, procurou-se desenvolver uma mudança de visão acerca do próprio trabalho e seu contexto, primeiro passo para se levar adiante o processo coletivo de transformação $0^{6}$. Visto que a relação dialógica possibilita autocrítica e modificação de representações ${ }^{4,5}$. Logo na sequência, indagou-se a respeito do sentido do trabalho, considerando que o tom dominante dos diálogos se voltava, na maior parte do tempo, para as adversidades no trabalho. 
(P) Então, vamos entender, qual o sentido do trabalho pra vocês?

Eu tenho o maior prazer em trabalhar, não fico esperando o final de semana ansiosamente, cinco horas da tarde, sexta-feira para ir embora, não fico. Adoro o que a gente faz, que em geral é tentar estudar, fazer perguntas, responder perguntas, a relação com os alunos. [...] Ler artigos, escrever projetos, discutir o resultado com os alunos, vir dar aula. (D8)

Não tem nada que me dê mais prazer do que o trabalho. [...] Porque o nosso sonho é fazer pesquisa e dar aula! (D6)

Você depende de seu estado emocional para resistir. Na verdade, é resistência [...] Meus alunos são ótimos, o grupo de professores se dá muito bem, colabora. Então acaba que essas coisas me alimentam mais que a parte negativa. (D8)

Todos os participantes se reportavam à parte do trabalho que gera prazer e satisfação como àquela que diz respeito à relação com os alunos, bem como à prática de pesquisas, principalmente em laboratórios. Ademais, em todas as reuniões das Oficinas ganhou destaque a menção positiva da relação entre os próprios docentes como fator de resistência às adversidades. Trata-se do caráter ambíguo do trabalho: o conhecimento, o trabalho intelectual e, principalmente, a relação com os alunos e colegas são elementos que contribuem para a autorrealização e, por conseguinte, para a produção de saúde. Problematizou-se sobre os sentidos e a ambivalência do trabalho docente: de um lado o trabalho emancipador e de outro o trabalho opressor que gera sofrimento.

No meu laboratório eu não posso pegar mais aluno porque não tem espaço, que é mínimo. Eu uso o espaço de laboratório de outro professor, que dá espaço para quatro professores usarem [...] Não tem espaço, não tem estrutura. A gente faz o que pode. No limite pode causar um acidente, muito fácil. (D1)

Debateu-se a necessidade de vigilância nos locais de trabalho, considerando principalmente o tema da biossegurança em laboratórios, com a preocupação de não reduzir os diálogos sobre saúde unicamente aos processos de adoecimento, riscos e acidente ${ }^{24}$.

(P) E isso tem um efeito na saúde?
Exatamente. As pessoas que têm problemas de saúde, às vezes, nem percebem que estão vivendo esse problema. Muitos até se recusam a aceitar que podem ter um problema, mas quando procuram ajuda se deparam com essa situação, que é um quadro que é proveniente das condições de tudo isso que a gente vive. (D6)

E o nível de ingestão de medicamento eu sei que é alto, de antidepressivo, para poder lidar com aquilo. (D3)

O que eu tenho visto com os meus colegas, acho que um estresse muito grande, ele começa a desencadear uns transtornos de humor, então as pessoas estão impacientes, estão sem limites, então assim, estourando por qualquer coisa [...] Tá todo mundo muito a flor da pele. (D1)

Devendo. A gente está sempre devendo. (D2)

Ouviu-se dos professores expressões como "frustração", "estresse", "variação de humor", "tristeza" e "medo". Quando o tema é saúde docente, ganha destaque, tanto na literatura quanto no ponto de vista dos próprios professores, referências à saúde mental $^{19,20}$. Foram problematizadas as muitas falas de se sentirem em dívida com o trabalho, refletiu-se sobre o contexto de trabalho, um contexto que adoece. Logo, interpreta-se que não se trata de uma dívida do professor com o seu trabalho, mas, sim, um trabalho em dívida com ele. O trabalho docente em universidades, em sua forma atual de organização, institui um conjunto de faltas com o professor. Aspectos como precarização e intensificação contribuem para a sobrecarga das atividades docentes, suscitando um quadro difuso de queixas de saúde.

No que concerne ao tema da ingestão de medicamentos, não foram localizados estudos na literatura atual. Não obstante, o estudo de Oliveira Filho e colaboradores ${ }^{35}$ evidenciou o consumo habitual de álcool entre professores universitários com episódios de consumo excessivo, sendo considerado pelos autores um quadro preocupante. Assim, levou-se a termo o compromisso de incluir a questão da ingestão de medicamentos no inquérito sobre saúde docente que estava sendo elaborado na época por epidemiologistas da instituição dos pesquisadores. Nesse ponto, vale mencionar a importância dos estudos quali-quantitativos na área da saúde coletiva. Por certo que as Oficinas (abordagem qualitativa) foram fundamentais para fornecer questões a serem incluídas no protocolo epidemiológico de investigação (abordagem quantitativa), pois ambas as modalidades se complementam. 
A certa altura do diálogo estimulou-se os docentes a falarem sobre questões relacionadas ao tempo que deveria ser dedicado a pausa, descanso e férias. Debateu-se a intensificação do trabalho do professor.

Não adianta, não são as férias que vão descansar ou 15 dias de recesso. (D1)

(P) Mas fala mais sobre isso. Por que quinze dias não são suficientes?

A gente não desliga totalmente. (D1)

Exatamente isso, quando você começa a desligar, acabam suas férias. Eu sinto isso, a gente custa realmente a relaxar. (D8)

Foram recorrentes nas Oficinas relatos de docentes acerca das horas excedentes de trabalho após a jornada formal e da frustração por não conseguirem dar conta de todas as tarefas do trabalho. No decurso das quatro reuniões ocorreram relatos de comportamentos atípicos, como dormir depois de duas horas da madrugada ou acordar às quatro horas da manhã, principalmente quando estão sob a pressão de prazos. As várias faces da intensificação do trabalho foram problematizadas e os próprios professores estabeleciam a relação com a saúde. Alguns participantes foram enfáticos ao afirmarem privação do sono e estresse ${ }^{36}$. Reiterou-se, com Pina e Stotz ${ }^{37}$, que a problemática da intensificação do trabalho está relacionada, centralmente, à determinação social do processo saúde-doença e implicada no processo de trabalho. Além disso, os autores sustentam que o trabalho intensificado tende a enfraquecer a capacidade coletiva do trabalhador para defender sua saúde e, principalmente, questionar as determinações dos problemas. Nesse sentido, emergiu o debate sobre a importância dos espaços coletivos de diálogo que promovem a reflexão sobre a experiência do trabalho e a defesa da saúde.

(P) Isso também a gente vem verificando, que os espaços coletivos de fala e de escuta no trabalho, eles aliviam essa situação.

Imagino que sim, mas eu não sei o que é isso. Afora essa experiência que a gente está tendo aqui, eu não conheço. (D1)

Eu acho que é um alívio, quando você começa a falar e vê que, talvez, o que você sente é o mesmo que o outro sente, isso que eu acho que é importante. De você ver que talvez o seu sentimento é um sentimento comum, então eu acho que esse momento de debate é importante também para isso. (D6)
Sob a ótica da metodologia empreendida, pretende-se que os trabalhadores alcancem o progressivo domínio sobre o seu trabalho, suas dimensões físicas, seu tempo e espaço, suscitando o alargamento da capacidade coletiva de análise e autonomia de ação. No entanto, no decorrer das reuniões, verificou-se que predominam estratégias e saídas individuais para se resolver problemas relativos ao trabalho e à saúde. Assim, incentivou-se o debate sobre mudanças coletivas no trabalho.

(P) A gente quer, de fato, gerar algum tipo de mudança. O que pode ser feito?

Senão não fazia sentido né? Mostra as propostas, que vocês têm mais experiência nisso, para a gente poder debater o que é possível ser implementado. Eu acho que deve ter, conhecendo o nosso público, uma grande resistência ainda, mas acho que é uma coisa que a gente tem que ir debatendo. (D2)

Observe-se que esse diálogo aconteceu na última Oficina, logo problematizou-se que mudanças deveriam ser construídas de forma partilhada, entre professores e os pesquisadores deste estudo. Ponderou-se que promover mudanças no trabalho não é processo simples, pois requer participação e dedicação. Desse modo, como desdobramento das Oficinas, os professores organizaram um seminário aberto na UX para restituição coletiva dos dados obtidos (os mesmos que foram aqui apresentados), um diálogo ampliado envolvendo todo o Instituto. Instalou-se um clima de questionamento a respeito das condições de trabalho e saúde, com potencial para estimular a participação coletiva para se alcançar mudanças. Além do mais, foi colocada em curso a aplicação de um inquérito epidemiológico no instituto, desenvolvido por equipe interdisciplinar com a participação dos docentes. Destarte, prosseguiu-se com a preocupação em se consolidar um programa de intervenções como parte de uma Comunidade Ampliada de Pesquisa ${ }^{6,29}$.

\section{Considerações finais}

No plano estrutural, entende-se que os problemas relacionados ao trabalho e à saúde docente, existentes no âmbito das Ifes no Brasil, estão condicionados a uma profunda transformação no âmbito do aparelho de Estado e a mudanças na esfera do modo de produção social, já que expressam as contradições do atual modelo capitalista de educação ${ }^{38}$.

No plano local, enfrenta-se o desafio do desenvolvimento de uma abordagem metodológica de caráter 
dialógico e participativo, correspondente ao pressuposto teórico de que o trabalhador se constitui em sujeito do conhecimento. Embora circunscrito a um grupo de oito docentes, identificaram-se temas importantes alusivos à atual configuração do trabalho em universidades públicas que foram problematizados em um processo coletivo de coanálise. No que tange aos limites do estudo, pode-se mencionar a dificuldade de agenda dos docentes, o que levou à periodicidade mensal de reuniões, limitando a capacidade coletiva de reflexão e aprofundamento dos temas. Por fim, confirma-se que processos educativos no trabalho não são lineares e se realizam na temporalidade e perspectiva dos próprios coletivos de trabalho.

\section{Contribuições de autoria}

Souza KR, Rodrigues AMS, Felix EG e Simões-Barbosa RH participaram de todas as etapas do estudo: levantamento, análise e interpretação dos dados; elaboração do manuscrito; revisão crítica e aprovação da versão a ser publicada. Santos MBM, Fernandez VS e Barros WO participaram do levantamento, análise e interpretação dos dados, elaboração do manuscrito e revisão crítica. Todos os autores assumem integral responsabilidade pelo trabalho publicado.

\section{Referências}

1. Marx K. O Capital: livro I. São Paulo: Boitempo; 2013.

2. Thiollent M. Crítica metodológica, investigação social e enquete operária. $4^{\mathrm{a}}$ ed. São Paulo: Polis; 1985.

3. Alves JCL, Jackson Filho JM. Trabalho, saúde e formação política na enquete operária de Marx. Trab Educ Saude. 2017;15(1):13-31.

4. Freire P. Extensão ou comunicação? $10^{\mathrm{a}}$ ed. Rio de Janeiro: Paz e Terra; 1988.

5. Freire P. Educação como prática da liberdade. $14^{\mathrm{a}}$ ed. Rio de Janeiro: Paz e Terra; 1983.

6. Oddone I, Marri G, Gloria S. Ambiente de trabalho: a luta dos trabalhadores pela saúde. São Paulo: Hucitec; 1986.

7. Souza KR, Mendonça ALO. Saúde do trabalhador e educação: reflexões a partir do modelo operário de conhecimento. Trab Necessario. 2013;11(17):1-32.

8. Muniz HP, Brito J, Souza KR, Athayde M, Lacomblez M. Ivar Oddone e sua contribuição para o campo da Saúde do Trabalhador no Brasil. Rev Bras Saude Ocup. 2013;38(128):280-91.

9. Brito J, Athayde M. Trabalho, educação e saúde: o ponto de vista enigmático da atividade. Trab Educ Saude. 2003;1(2):239-65.

10. Masson L, Gomes L, Brito J. Encontros sobre o trabalho: reflexões sobre o uso desta ferramenta metodológica em pesquisas em unidades de tratamento intensivo neonatais. Laboreal. 2015;11(1):23-38.

11. Leher R. Crise estrutural e função social da universidade pública. Temporalis. 2010;1:15-39.

12. Maués O. A reconfiguração do trabalho docente na educação superior. Educar em Revista. 2010;(especial 1):141-60.

13. Vieira EMF, Bellen HMV, Fialho FAP. Universidade em tempo de mudança. Cad EBAPE BR. 2006;4(3):1-7.
14. Chaui M. A universidade pública sob nova perspectiva. Rev Bras Educ. 2003;(24):5-15.

15. Léda DB, Mancebo D. REUNI: heteronomia, precarização da universidade e do trabalho docente. Educ Realidade. 2009;34(1):49-64.

16. Santana MA, Druck MG. Terceirização e degradação do trabalho nas universidades brasileiras. Margem Esquerda. 2015;25:52-8.

17. Pizzio A, Klein K. Qualidade de vida no trabalho e adoecimento no cotidiano de docentes do Ensino Superior. Educ Soc. 2015;36(131):493-513.

18. Cruz RM, Lemos JC, Welter MM, Guisso L. Saúde docente, condições e carga de trabalho. REID. 2010;4:147-60.

19. Gradella Júnior O. Sofrimento psíquico e trabalho intelectual. Cad Psicol Soc Trab. 2010;13(1):133-48.

20. Coutinho MC, Magro MLPD, Budde C. Entre o prazer e o sofrimento: um estudo sobre os sentidos do trabalho para professores universitários. Psicol Teor Prat. 2011;13(2):154-67.

21. Silva Júnior, JR, Sguissardi V, Silva EP. Trabalho intensificado na universidade pública brasileira. Univ Soc. 2010;45(9):9-25.

22. Souza KR, Mendonça ALO, Rodrigues AMS, Felix EG, Teixeira LR, Santos MBM, Moura M. A nova organização do trabalho na universidade pública: consequências coletivas da precarização na saúde dos docentes. Cien Saude Colet. 2017;22(11):3667-76.

23. Bosi AP. A precarização do trabalho docente nas instituições de ensino superior do Brasil nesses últimos 25 anos. Educ Soc. 2007;28(101):1503-23.

24. Laurell AC, Noriega M. Processo de produção e saúde: trabalho e desgaste operário. São Paulo: Hucitec; 1989. 
25. Guida HFS, Souza KR, Santos MBM, Silva SMCL, Silva VP. As relações entre saúde e trabalho dos agentes de combate às endemias da Funasa: a perspectiva dos trabalhadores. Saude Soc. 2012;21(4):858-70.

26. Brandão CR. Pesquisa participante. São Paulo: Brasiliense; 1984.

27. Gramsci A. Cadernos do cárcere. $4^{\mathrm{a}}$ ed. Rio de Janeiro: Civilização Brasileira; 2006.

28. Brandão CR, Streck DR. Pesquisa participante: a partilha do saber. São Paulo: Ideias \& Letras; 2006.

29. Souza KR, Fernandez VS, Teixeira LR, Larentis AL, Mendonça ALO, Felix EG, et al. Cadernetas de saúde e trabalho: diários de professores de universidade pública. Cad. Saude Publica (Online). 2018;34(3):e00037317.

30. BRASIL. Decreto $n^{\circ} 6.096$, de 24 de abril de 2007. Institui o Programa de Apoio a Planos de Reestruturação e Expansão das Universidades Federais - REUNI. Brasília, DF: Presidência da República, 2007.

31. Mancebo D. Crise político-econômica no Brasil: breve análise da educação superior. Educ Soc. 2017;38(141):875-92.
32. Druck G. Trabalho, precarização e resistências: novos e velhos desafios? Cad CRH. 2011;24(spe1):37-57.

33. Ruza FM, Silva AS, Pádua KC. Ser professor universitário: identidades construídas entre aspectos de satisfação e insatisfação profissional. Linhas Críticas. 2015;21(44):179-98.

34. Araújo TM, Sena IP, Viana MA, Araújo EM. Malestar docente: avaliação de condições de trabalho e saúde em uma instituição de ensino superior. Rev Baiana Saude Publica. 2005;29(1):6-21.

35. Oliveira Filho A, Netto-Oliveira ER, Oliveira AAB. Qualidade de vida e fatores de risco de professores universitários. Rev Educ Fis. 2012;23(1):57-67.

36. Ferreira RC, Silveira AP, Sá MAB, Feres SBL, Souza JGS, Martins AMEBL. Transtorno mental e estressores no trabalho entre professores universitários da área da saúde. Trab Educ Saude. 2015;13(1):135-55.

37. Pina JA, Stotz EN. Intensificação do trabalho e saúde do trabalhador: uma abordagem teórica. Rev Bras Saude Ocup. 2014;39(130):150-60.

38. Leher R, Motta VC, Vittoria P. Educação e mercantilização em meio à tormenta políticoeconômica do Brasil. Germinal. 2017;9(1):14-24. 